\title{
Selection of the technologically most appropriate variant of the solar photovoltaic (PV) water supply system by using multi-criteria methods PROMETHEE and GAIA
}

\author{
Bojan Đurin ${ }^{1} \cdot$ Lucija Nađ $^{1}$ (D)
}

Received: 8 February 2017 / Accepted: 5 July 2018 / Published online: 16 July 2018

(c) The Author(s) 2018

\begin{abstract}
Nowadays, technical directors, operative engineers and managers in utility companies often meet with many variants of various types of water supply systems. Such a task is becoming complicated if solar photovoltaic (PV) energy is used as an energy source, due to its stochastic nature. This paper will present the use of the multi-criteria methods PROMETHEE and GAIA for the case of technological criteria. The aim of the paper is finding a technologically most appropriate variant of the observed urban water supply system (UWSS), given that the resulting solution differs according to the size of certain parts. It should be noted that the observed UWSS consists of PV generator and inverter (subsystem PV), pump station (subsystem PS) and water reservoir (subsystem W). In addition, this paper explains the scientifically innovative and applicable methodology for sizing the UWSS driven by PV energy.
\end{abstract}

Keywords Water supply $\cdot$ Solar photovoltaic energy $\cdot$ Variant $\cdot$ PROMETHEE $\cdot$ GAIA

\section{Introduction}

The usage of solar photovoltaic (PV) energy has special importance, not only in urban water supply systems, but also for the entire human population in the world when it comes to the distribution of energy from renewable sources in hard-to-reach places (or remote areas). If a location has a sufficient quantity of water, it should be noted that electricity supply for its abstraction, further distribution and use can be a problem. PV energy is particularly suitable for energy supply for water supply systems in rural areas because there are locations where classical power network is not available or has limited availability. In this situation, especially in remote areas and on islands, PV energy solves this energy and water distribution problem. In doing so, the emphasis is not only on the use of PV energy, but also on improving the performance of pumping stations and reservoirs, as well as

Lucija Nađ

lucijananad@gmail.com

Bojan Đurin

bojan.djurin@gfv.hr

1 Faculty of Geotechnical Engineering, University of Zagreb, Hallerova aleja 7, 42000 Varaždin, Croatia the remaining parts of the water supply system (for the most part that refers to pipelines). Nowadays, in addition to meeting the technological and economic criteria, it is necessary to meet other criteria, such as environmental, social, political and other. Among other procedures, multi-criteria methods are used for the solution of such issues. In this case, multicriteria methods, i.e., PROMETHEE and GAIA methods, will be used only for technological criteria, due to the aim and scope of this paper.

Urban water supply system (UWSS) driven by PV energy usually consists of three main parts/subsystems (Fig. 1). These are solar photovoltaic generator and inverter with corresponding equipment-subsystem PV, pumping station with related equipment-subsystem PS, and water reservoir-subsystem $\mathrm{W}$. These subsystems achieve an integrated technological system, and they are functionally interconnected.

Subsystem PV turns solar energy from the sun into electrical energy $E_{\text {el,PV }}$ in the subsystem PV, which is used for water pumping into the water reservoir overcoming geodetic height $H_{\mathrm{g}}$, i.e., manometric height $H_{\mathrm{PS}}$. Solar energy is of stochastic nature in view of intensity and duration. Therefore, the role of water reservoir as a reservoir of water, i.e., energy, in conjunction with possible electric energy production from the subsystem PV, is crucial in providing the 
Fig. 1 Urban water supply system (UWSS) driven by solar photovoltaic (PV) energy. (modified from Đurin 2014)

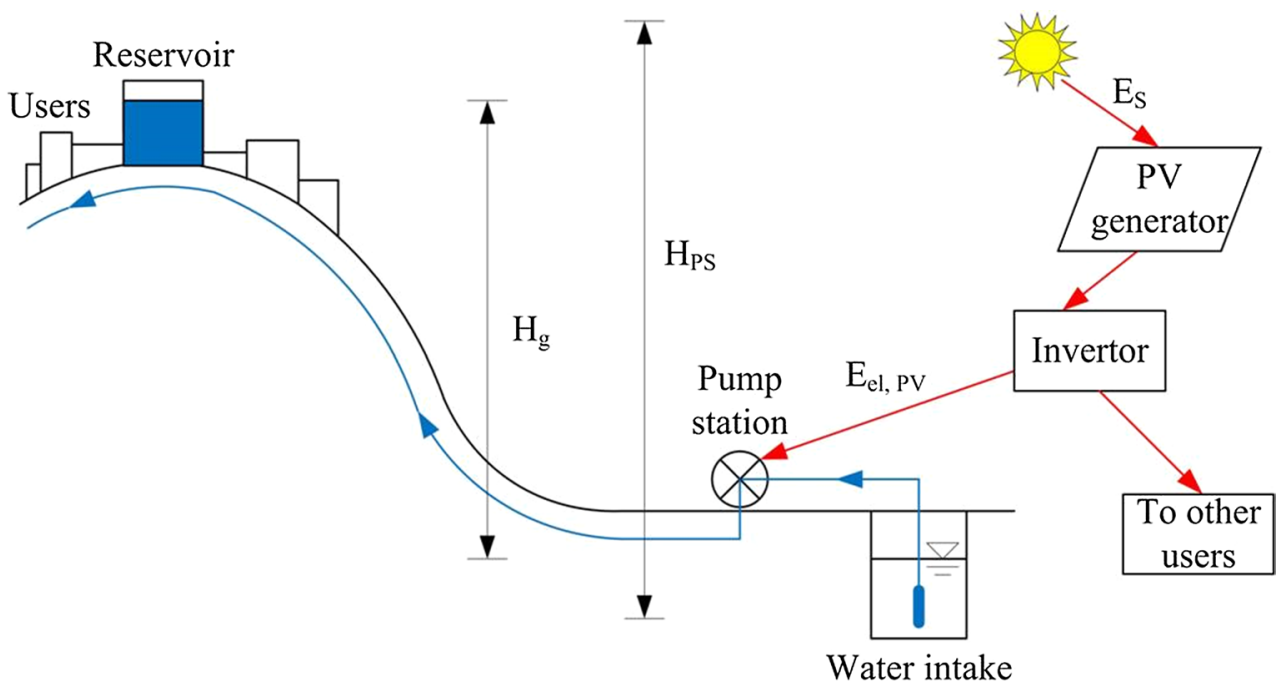

continuity and safety of water supply. Therefore, the system must be appropriately planned and sized, i.e., the methodology described in this paper must be applied. Given the scope and purpose of this paper, the detailed procedures and terms for dimensioning individual parts of the system will not be explained, but they can be found in Đurin and Margeta (2014) and Đurin (2014).

\section{Methodology}

\section{Definition of the critical period method (CPM)}

The difference between the previous ways of sizing of the water supply systems using the critical period method (CPM) is that instead of one critical period which relates to the maximum daily consumption of water, the CPM considers three critical periods. In the case of using PV energy for urban water supply system (UWSS), these critical periods are: critical period for sizing the subsystem PV (PV generator and inverter) $t_{\mathrm{Pel}(i)}^{*}$, critical period for sizing the subsystem PS (pumping station) $t_{\mathrm{PS}(i)}^{*}$ and critical period for sizing the subsystem $\mathrm{W}$ (water reservoir) $t_{\mathrm{W}(i)}^{*}$ (Đurin 2014). This provides security and reliability of the operation of each subsystem, since the sizing is performed with respect to the critical period/periods of each subsystem. In so doing, CPM produces operating integrity and technological reliability of such type of the UWSS. In other words, if critical period(s), i.e., day (days), for every subsystem are satisfied with regards to the required power of PV system, the pump station capacity and power, and water reservoir volume, will also be satisfied in all other days in the years. As a matter of fact, there will be surplus of the produced energy, but this comes in favor with providing the technologic reliability of the system.

The first critical period $t_{\mathrm{Pel}(i)}^{*}$ is defined for determining sufficient power of subsystem PV $P_{\mathrm{el}, \mathrm{PV}}$, which will provide enough electric energy for pumping water into the reservoir every day of the analyzed year, in accordance with the regime of daily water consumption in a settlement. This is the period (periods) in which the difference $\Delta V_{\operatorname{Pel}(i)}$ between the daily required water for population needs $V_{\text {daily }(i)}$ and daily pumped water $V_{\mathrm{PS}(i)}$ is minimum for every day of the year with regard to the balancing period $t_{\mathrm{b}}$ :

$$
\begin{aligned}
& \Delta V_{\mathrm{Pel}(i)}=V_{\mathrm{PS}(i)}-V_{\mathrm{daily}(i)}, \\
& \quad i=1,2, \ldots, 365 \Rightarrow \min \Delta V_{\mathrm{Pel}(i)} \Rightarrow t_{\mathrm{Pel}(i)}^{*},
\end{aligned}
$$

where $\Delta V_{\operatorname{Pel}(i)}$ is acceptable difference in practical application, which is usually or close to 0 .

The duration of daily solar radiation $T_{\mathrm{s}(i)}$ determines the possible operating period of the pumping station. This introduces the second critical period (periods) $t_{\mathrm{PS}(i)}^{*}$ for determining the capacity or power of the pumping station. $t_{\mathrm{PS}(i)}^{*}$ is the critical period (periods) in which the relationship between the daily consumption of water in a settlement $V_{\text {daily(i) }}$ and duration of daily solar radiation $T_{\mathrm{s}(i)}$ is minimum:

$\max Q_{\text {daily }}=\frac{V_{\text {daily }(i)}}{T_{\mathrm{s}(i)}} \Rightarrow t_{\mathrm{PS}(i)}^{*}$.

It is understood that adequate PV subsystem power $P_{\mathrm{el}, \mathrm{PV}}$ is provided, with respect to the corresponding critical period $t_{\mathrm{Pel}(i)}^{*}$. Thus, in accordance with the rules of the profession, the capacity of the pumping station is determined that can pump the required quantity of water $Q_{\text {hour }(t)}\left(\mathrm{m}^{3} / \mathrm{h}\right)$, which in 
fact represents the highest flow per hour during a typical year in the planning period.

The critical period (periods) $t_{V(i)}^{*}$ for determining the reservoir volume $V$ is the period in which maximum daily water consumption in a settlement $V_{\text {daily }(i)}$ for each day $i$ is maximum during the year, where the intensity of solar radiation $E_{\mathrm{s}(i)}$ and its duration $T_{\mathrm{s}(i)}$ are satisfactory, so that the subsystem $\mathrm{PV}$ can produce sufficient electricity to drive the main pumping station. It is understood that adequate PV subsystem power $P_{\text {el,PV }}$ is provided with respect to the corresponding critical period $t_{\mathrm{Pel}(i)}^{*}$ and sufficient subsystem PS capacity $Q_{\mathrm{PS}}$, also with respect to the corresponding critical period $t_{\mathrm{PS}(i)}^{*}$ :

$\max V_{\text {daily }(i)} \Rightarrow t_{\mathrm{W}(i)}^{*}$.

Each of the three critical periods is determined with regard to a certain balancing period (periods) $t_{\mathrm{b}}$, i.e., equalization periods of the required and pumped water or equalization periods of the required and produced energy. The shortest possible balancing period $t_{\mathrm{b}}$ is 1 day. When the balancing period $t_{\mathrm{b}}$ is longer, the solution is in principle safer, because longer balancing period reduces the impact of extreme low insolation $E_{s}$ on the required power of the subsystem PV, $P_{\text {el,PV}}$. In addition, the system is more efficient with regard to the possibility of using solar radiation, since the sum of the total available solar insolation is greater when $t_{b}$ is longer, because it eliminates the impact of extreme maximum individual daily duration and intensity of solar radiation. Also, possible failures, energy lacks or other interruptions are being diminished by extension of the balancing period. Therefore, the solution is safer and more rational in view of sizing the subsystem PV. This means that the required water amount can be pumped with a lower installed power of the subsystem PV, Đurin and Margeta (2014).

\section{Multi-criteria methods PROMETHEE}

The family of PROMETHEE methods were developed by Brans and Vincke (1985) to help a decision-maker rank partially (PROMETHEE I) or completely (PROMETHEE II) a finite number of options which are evaluated on a common set of non-commensurable multiple criteria (Mutikanga et al. 2011). PROMETHEE is an outranking method for a finite set of alternative actions to be ranked and selected among criteria which are often conflicting. PROMETHEE is also a quite simple ranking method in conception and application compared to the other methods for multi-criteria analysis (Brans et al. 1986). Alternatives are evaluated according to different criteria, which have to be maximized or minimized. Determination of the weights is an important step in most multi-criteria methods. It is assumed that the decision-maker is able to weigh the criteria appropriately, at least when the number of criteria is not too large (Macharis et al. 2004). For each criterion, the preference function translates the difference between the evaluations obtained by two alternatives into a preference degree ranging from zero to one. The alternatives evaluated will be generated as a function of the balancing period length (number of days) $t_{\mathrm{b}}$.

In the PROMETHEE I, the actions are ranked in partial order. If the estimated relation of "higher rank" for each node $a$ is defined, based on multi-criteria preference index for each $a \in A$, the following flows are obtained:

- Output flow:

$$
\Phi^{+}(a)=\frac{1}{n-1} \sum_{x \in A} \prod(a, x) .
$$

- Input flow:

$$
\Phi^{-}(a)=\frac{1}{n-1} \sum_{x \in A} \prod(x, a) .
$$

When the output flow is greater, $a$ dominates over other actions from $A$, with lower input flow fewer actions dominate over $a$. Some actions will be comparable, and some incomparable so that the PROMETHEE I gives partial relations, i.e., estimated relation of "higher rank" that gives important information to the decision-maker about the relations between actions. In the PROMETHEE II, actions are ranked in complete order (full ranking without incomparability). For every action $a \in A$, the resulting (net) flow is observed:

$\Phi(a)=\Phi+(a)-\Phi-(a)$

which is used in ranking of actions:

- $a$ has a higher rank than $b(a P(2) b)$ if $\Phi(a)>\Phi(b)$;

- $a$ is indifferent to $b(a I(2) b)$ if $\Phi(a)=\Phi(b)$.

The PROMETHEE II defines the complete relation where all the action from $\mathrm{A}$ are fully ranked, noting that in this relation part of information is lost, due to the balancing effects between the output and the input flow, which results in a higher degree of abstraction (Mladineo 2009).

\section{Multi-criteria methods GAIA}

Method Geometrical Analysis for Interactive Aid (GAIA) gives a geometric presentation of the results of PROMETHEE method, or methods PROMETHEE I and PROMETHEE II. The idea underlying this method is the reduction in a multidimensional problem to a two-dimensional one to enable planar presentation. The dimension of multi-criteria analysis is determined by the number of criteria (each criterion determines one of the vectors in such space), and if a geometric presentation is desired, the

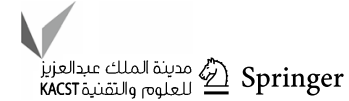


problem should be reduced to a two-dimensional image (a possible three-dimensional image would be confusing). In this reduction in dimension, a loss of information regarding the problem is inevitable. To minimize this loss as much as possible, the plane in which the geometrical presentation is given is determined by the two largest values typical for covariance matrix. GAIA provides data on the percentage of information given by such presentation. With the exception of an extremely unfavorable problem structure, the geometric presentation provides sufficiently high percentage of information for analyzing the problem. It is also possible to connect GAIA method with the method PROMETHEE II. PROMETHEE II requires that a certain weight $W_{j}$ be allocated to each criterion and that the complete order in set $\mathrm{A}$ be defined. The weights can also be displayed in the $(u, v)$ plane by using the so-called decision vectors which are aimed toward the highest ranking activities. In this way, by interactive changing of weights, it is possible to observe changes in rank, acquired by the method PROMETHEE II (Mladineo 2009). The importance of the decision-making criteria is geometrically represented with the vector length $\pi$, so that dominant criteria correspond to the vectors of greater absolute values. Summing the vectors that present the criteria leads to a summary vector whose direction and value describe the resulting action of the criteria. If the summary vector of criteria is of small absolute value in relation to the summary vector of another individual criterion, this indicates the conflict of criteria. It can be concluded that geometrical presentation of multi-criteria analysis is a very powerful "tool" and provides substantial assistance with problems characterized by partially or totally conflicting criteria, which is unfortunately frequent in the decision-making processes (Mladineo 2009).

Let $\left(A_{1}, A_{2}, \ldots, A_{i}, \ldots, A_{n}\right)$ be the projections of the $n$ points representing the alternatives, and let $\left(C_{1}, C_{2}, \ldots, C_{j}, \ldots, C_{k}\right)$ be the projections of the $k$ unit vectors of the coordinates axes of IR $^{k}$ representing the criteria. Figure 2 shows GAIA plane. Decision vector is marked with $\pi$. Ranking of the alternatives is defined with perpendicular on the vector $\pi$ from the point which defines individual alternative.

Then, the following properties hold (Brans et al. 1986):

- The longer a criterion axis in the GAIA plane, the more discriminating this criterion.

- Criteria expressing similar preferences are represented by axes oriented in approximately the same direction.

- Criteria expressing conflicting preferences are oriented in opposite directions.

- Criteria that are not related to each other in terms of preferences are represented by orthogonal axes.

- Similar alternatives are represented by points located close to each other.

- Alternatives being good on a particular criterion are represented by points located in the direction of the corresponding criterion axis.

\section{Case study}

This paper presents a hypothetical example of a settlement with a population equivalent of 8970 . The settlement is located on an island in the southern Mediterranean part of Croatia. It is in a hilly area of the island and has one water reservoir located at a ground elevation of $259 \mathrm{~m}$ above sea level. Water flows into the reservoir from the wet basin of the pump station. Water flows into the wet basin of the pump station by gravity from the spring. Total head of the pump station is $82.41 \mathrm{~m}$. The water quality is satisfactory and does not need treatment. The positions of

Fig. 2 Alternatives and criteria in the GAIA plane. (modified from Brans et al. 1986)

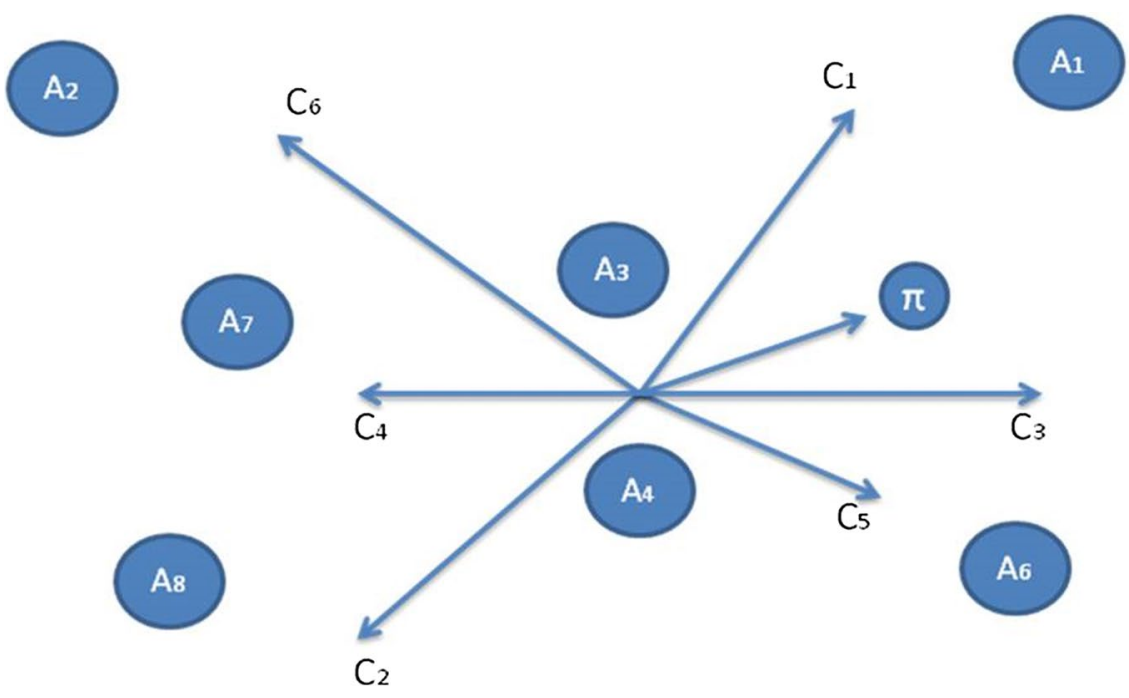


the basic facilities of the water supply system are shown in Fig. 3 (modified from District of Columbia Water and Sewer Authority 2013).

The analysis is conducted according to the presented methodology. The daily water consumption pattern through the year is shown in Fig. 4 (Đurin and Margeta 2014). Hourly water consumption pattern (Đurin and Margeta 2014) in the settlement is determined by the daily regime of consumption, as shown in Fig. 5.

For the considered location, the average pump head is $H_{\mathrm{PS}}=82.41 \mathrm{~m}$, average efficiency of the inverter and motor pump unit is $\eta_{\mathrm{MPI}}=0.75$, cell temperature coefficient is $\alpha_{\mathrm{C}}=0.005{ }^{\circ} \mathrm{C}^{-1}$, and temperature of the PV generator in standard test condition is $T_{0}=25{ }^{\circ} \mathrm{C}$. The average daily global radiation $E_{\mathrm{S}(i)}$ and average daily insolation period $T_{\mathrm{S}(i)}$ are shown in Fig. 6 (Đurin and Margeta 2014).
The average daily cell temperature $T_{\text {cell }(i)}$ and average daily ambient air temperature $T_{\mathrm{a}(i)}$ are shown in Fig. 7 (Đurin and Margeta 2014).

\section{Obtained results and discussion}

Based on the given data, by applying Eqs. (1)-(3), critical periods for all subsystems have been determined (Table 1). Also, by applying the previously presented methodology, the required PV generator power $P_{\mathrm{el}, \mathrm{PV}}^{*}$, required reservoir volume $V^{*}$ and power of the pump station $P_{\mathrm{PS}}^{*}$ are calculated (Table 2).

The required capacities of pump station $Q_{\mathrm{PS}}^{*}$, i.e., power of pump station $P_{\mathrm{PS}}^{*}$, are calculated by using the value of pump efficiency $\eta_{\mathrm{PS}}=0.90$ (Margeta 2010). The results obtained using the PROMETHEE, i.e., software package
Fig. 3 Case study schematic layout

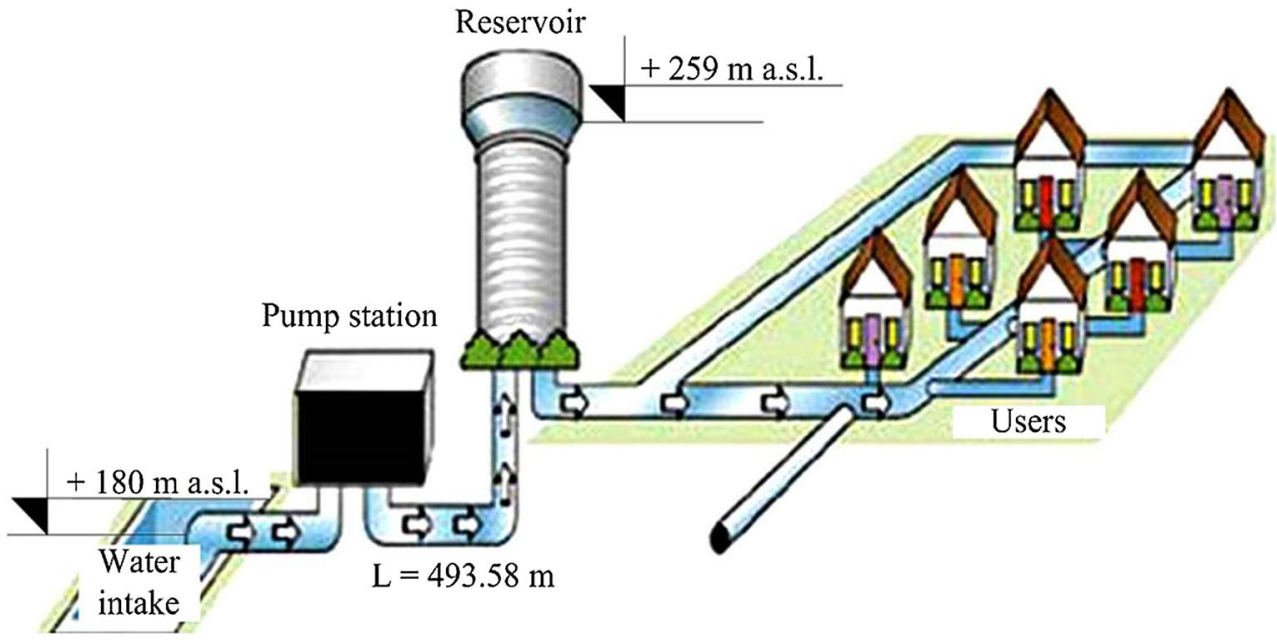

Fig. 4 Daily water demand during the year

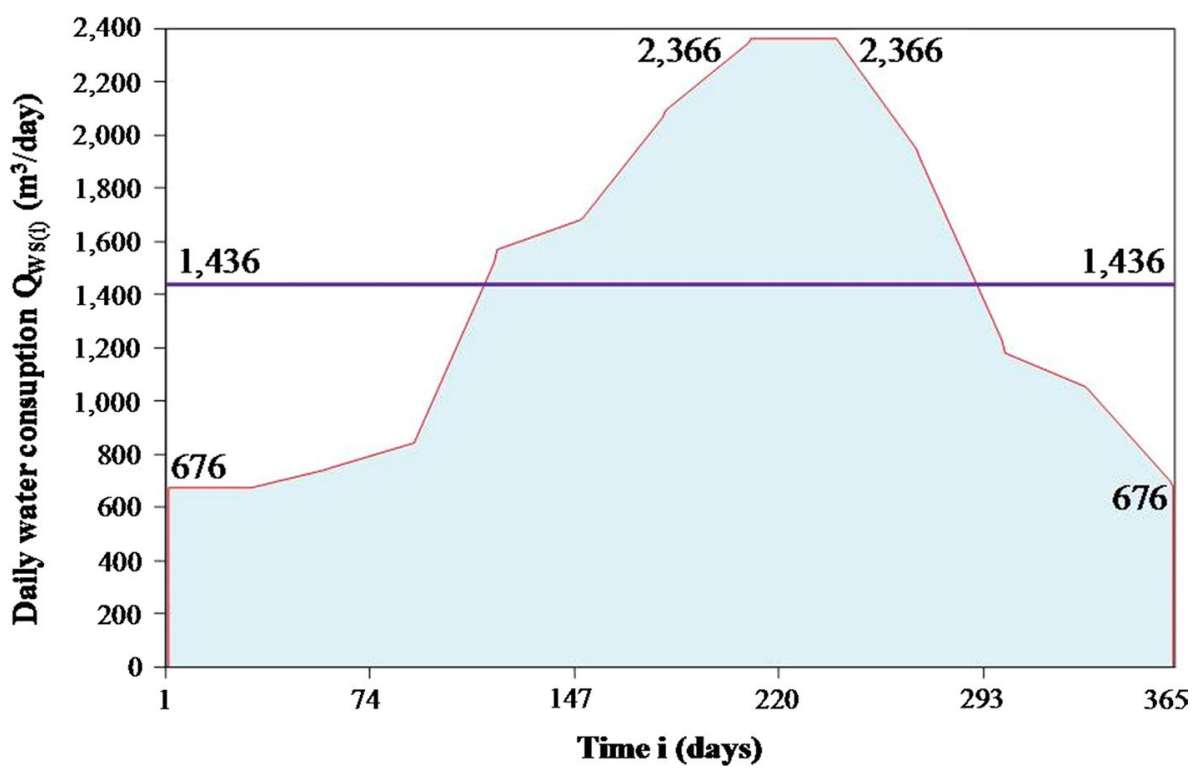

Time i (days) 
Fig. 5 Hourly water demand during typical day

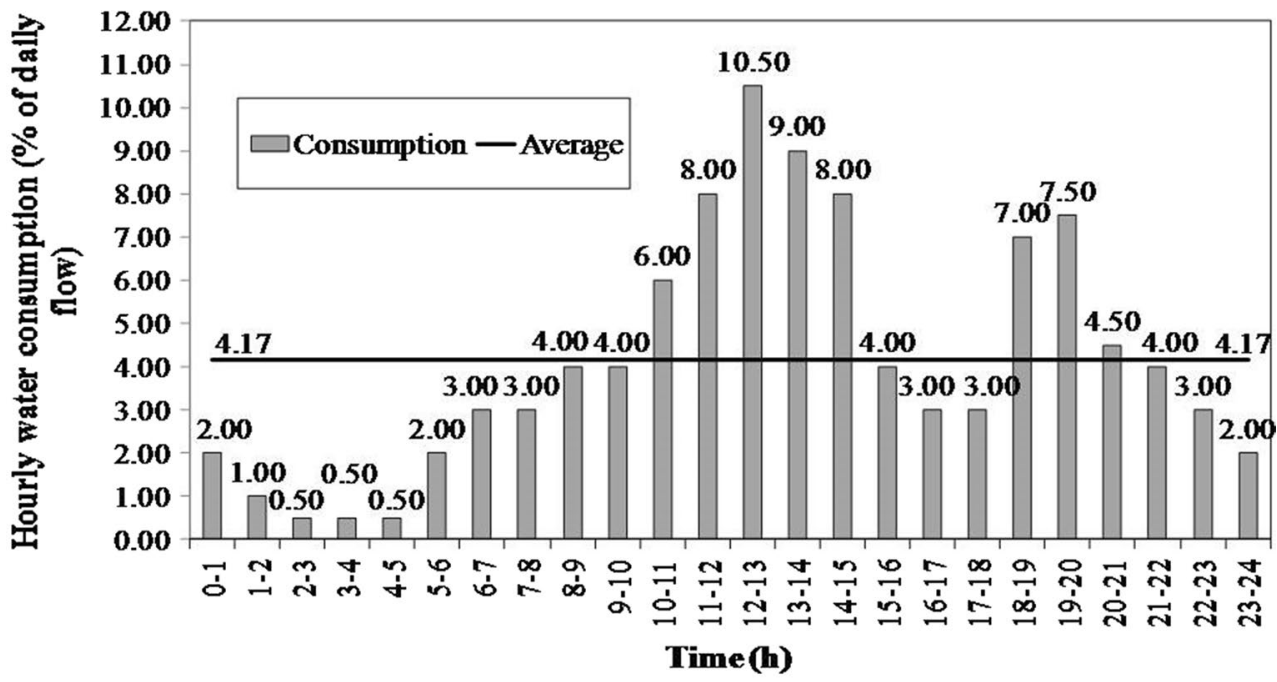

Fig. 6 Average daily solar insolation values

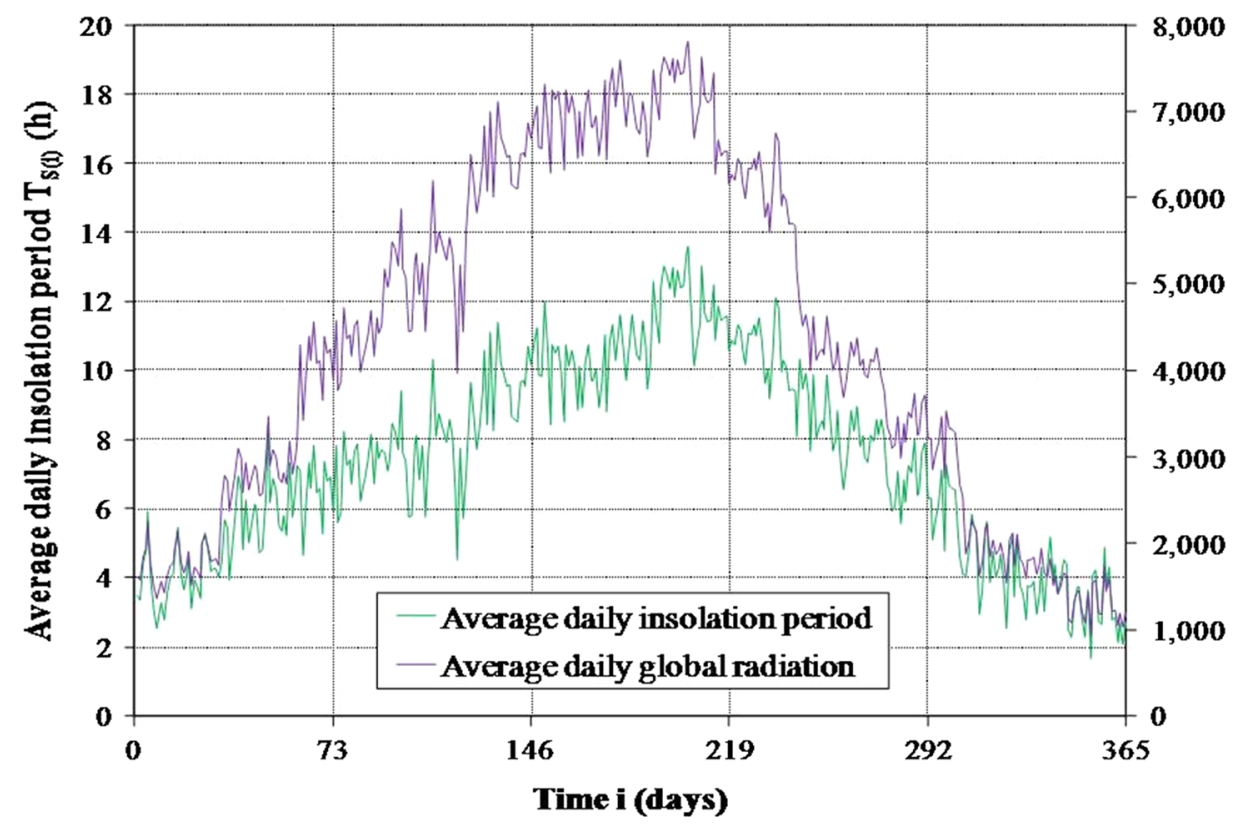

PROMETHEE (Mareschal 2014), are shown in Fig. 8. All three values of individual subsystems, i.e., power $P_{\text {el,PV }}^{*}$, volume $V^{*}$ and power $P_{\mathrm{PS}}^{*}$, have the same significance or weights equal to 0.33 (subsystem PV; $w_{\text {Pel,PV }}$, subsystem W; $w_{\mathrm{W}}$ and subsystem PS; $w_{\mathrm{PS}}$ ) for the unbiased analysis. Also, maximization of all values of individual subsystems for all balancing periods $t_{\mathrm{b}}$ was set as a necessary input condition.

Clear view of the obtained results is shown in Table 3.

It can be seen that Variant $2\left(t_{\mathrm{b}}=2\right.$ days $)$ is the most favorable given the value of the indicators, followed by variants 3,1, 4 and 5. Variant 2 significantly stands out compared to the remaining variants, so that based on the above said, it is technologically the most appropriate variant.
Accordingly to the presented methodology and in accordance with the explanation from Fig. 9, it could be seen that the results obtained by using PROMETHEE are overlapping with results obtained by using GAIA method. The point denoting Variant 2 is the closest perpendicularly to the decision vector, i.e., to its top.

However, the change of criteria weights would be a bare minimum for any decision-maker to see which of the obtained variants is the most important one or which one has the highest impact. Due to this, further course of discussion is in the direction of the sensitivity analysis, regarding impact of the change of criteria weights on the ranking of the obtained variants of solution. Table 4 
Fig. 7 Average daily cell temperature and average daily ambient air temperature
Table 1 Length of balancing period in accordance with critical days

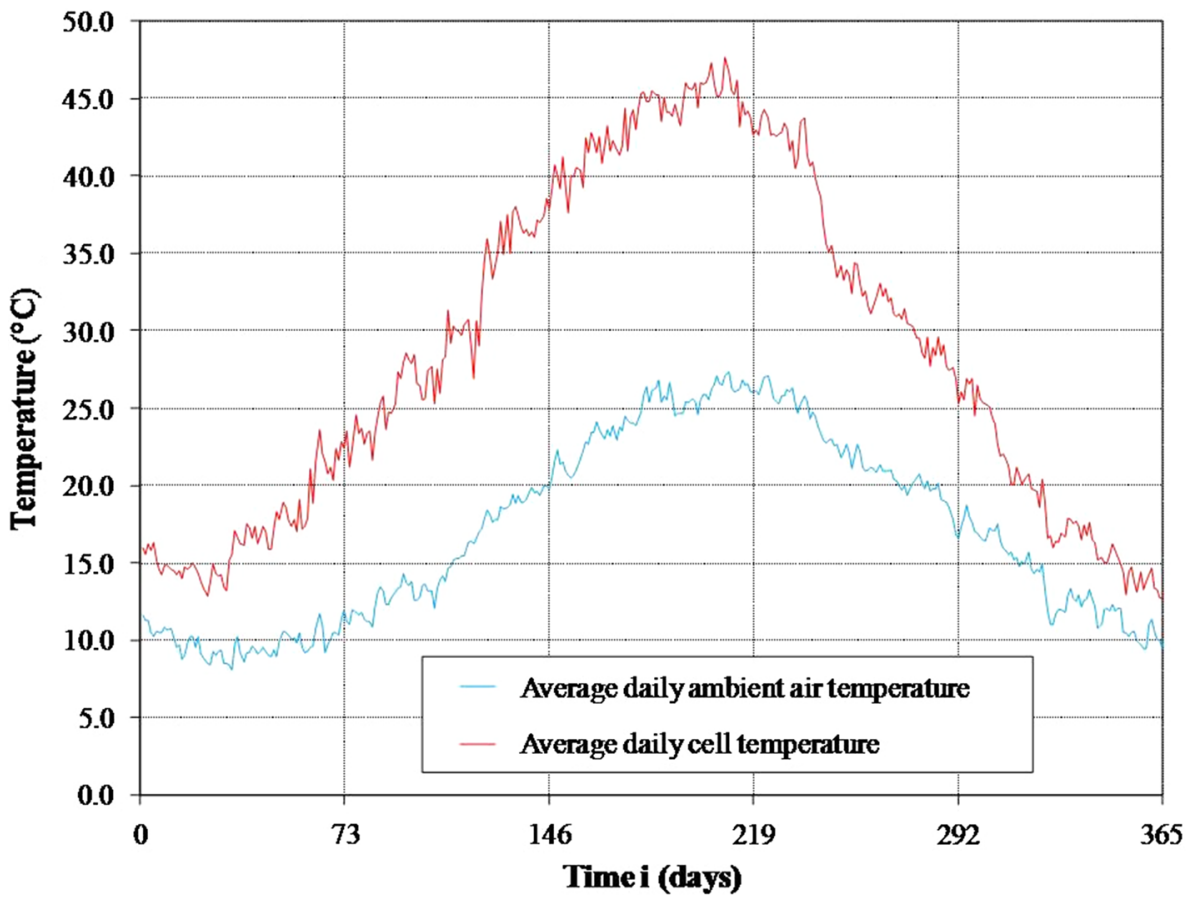

\begin{tabular}{llllll}
\hline Balancing period $t_{\mathrm{b}}$ (days) & 1 & 2 & 3 & 4 & 5 \\
\hline Critical periods (days in year) $t_{\mathrm{Pel}(i)}^{*}$ & 352 & $344-345$ & $344-346$ & $349-352$ & $348-352$ \\
Critical periods (days in year) $t_{\mathrm{W}(i)}^{*}$ & 244 & $244-245$ & $243-245$ & $243-246$ & $242-246$ \\
Critical period (days in year) $t_{\mathrm{PS}(i)}^{*}$ & 352 & $344-345$ & $344-346$ & $344-347$ & $343-347$ \\
\hline
\end{tabular}

Table 2 Sizes of subsystems for different balancing periods

\begin{tabular}{llll}
\hline $\begin{array}{l}\text { Balancing } \\
\text { periods } t_{\mathrm{b}} \\
\text { (days) }\end{array}$ & $\begin{array}{l}\text { Power } P_{\mathrm{el}, \mathrm{PV}}^{*} \\
(\mathrm{~kW})\end{array}$ & Volume $V^{*}\left(\mathrm{~m}^{3}\right)$ & Power $P_{\mathrm{PS}}^{*}(\mathrm{~kW})$ \\
\hline 1 & 512.50 & 1100 & 106.00 \\
2 & 477.82 & 1178 & 119.47 \\
3 & 443.87 & 1271 & 111.39 \\
4 & 419.80 & 1415 & 105.10 \\
5 & 403.45 & 1513 & 99.71 \\
\hline
\end{tabular}

shows different weights $w_{\mathrm{Pel}, \mathrm{PV}}, w_{\mathrm{W}}$ and $w_{\mathrm{PS}}$, and also a full rank $\Phi$ of obtained solutions, regarding different balancing periods $t_{\mathrm{b}}$.

The importance of the particular part of the subsystems was graded with size equal to 0.5 , while the other two subsystems were graded by 0.25 . Comparing with results from Table 3, i.e., with equal weights for all subsystems, it can be concluded that water reservoir has the biggest changes in order of particular alternatives, while for PV generator and inverter power and pump station power changes are not so drastic. Moreover, variant $t_{\mathrm{b}}=2$ is the best ranked for the

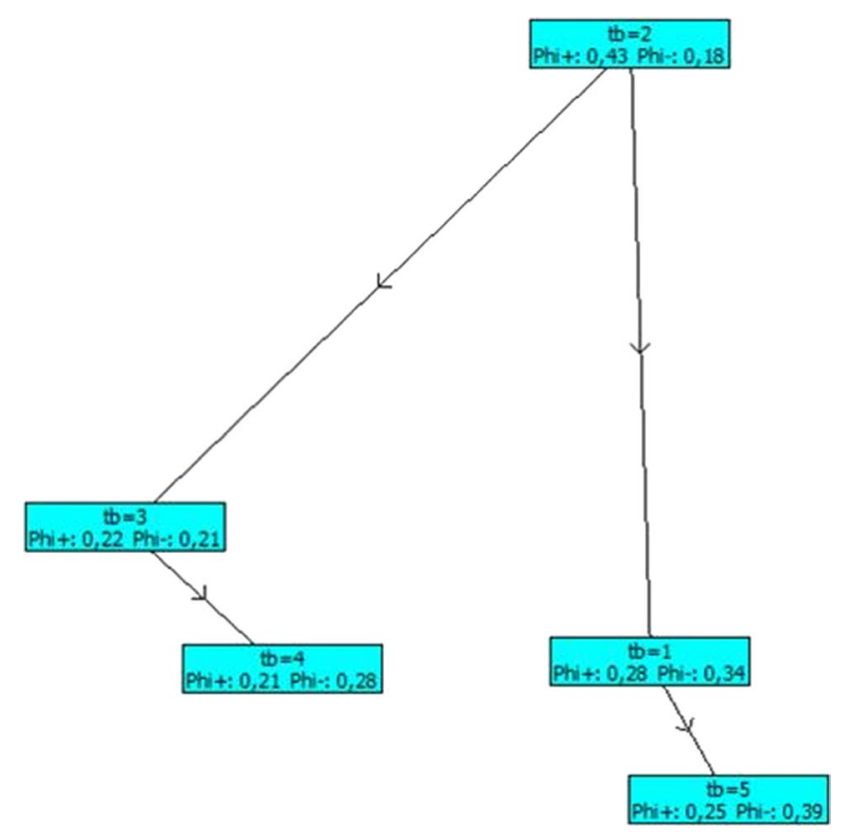

Fig. 8 Visual view of the results obtained by using the method PROMETHEE 
Table 3 Results obtained by using the method PROMETHEE

\begin{tabular}{llll}
\hline Variant & \multicolumn{1}{l}{$\Phi$} & $\Phi+$ & $\Phi-$ \\
\hline$t_{\mathrm{b}}=2$ & 0.2531 & 0.4304 & 0.1773 \\
$t_{\mathrm{b}}=3$ & 0.0066 & 0.2204 & 0.2138 \\
$t_{\mathrm{b}}=1$ & -0.0618 & 0.2764 & 0.3383 \\
$t_{\mathrm{b}}=4$ & -0.0655 & 0.2114 & 0.2769 \\
$t_{\mathrm{b}}=5$ & -0.1323 & 0.2547 & 0.3871 \\
\hline
\end{tabular}

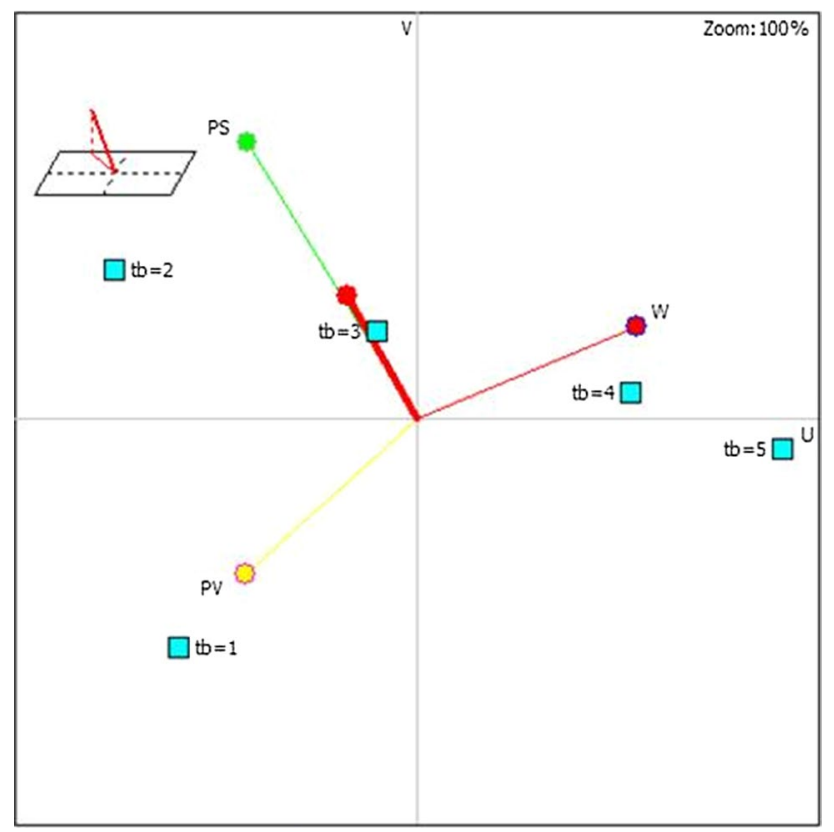

Fig. 9 Results obtained by using the method GAIA

other two mentioned subsystems (PV generator and inverter power and pump station power), despite changing of the weights.

\section{Conclusions}

Technological reliability of the water supply system, which is driven by solar photovoltaic energy, is provided by the application of critical period method and by taking into account that water reservoir is not only water storage, but also energy storage by the connection with PV generator. Sensitivity analysis has shown that the size of the water reservoir has important impact on the choice of the technologically reliable variant of the observed urban water supply system (UWSS). In other words, bigger size means bigger reliability of the UWSS. Possible failures, stochastic nature of insolation, energy lacks and other interruptions of the water supply which may appear are compensated with water reservoir. The safety of energy inflow, i.e., electric energy, may be raised by covering with energy from the existing electric grid, especially in the so-called peak period of the day (in the morning, noon and evening) and year (during summer/touristic season). It should be noted that every water supply system has internal source of energy, which could be used for this purpose. This can be implied by putting small hydropower turbines into the pipelines.

The paper shows that the issue of selecting the technologically most appropriate variant of the water supply systems, taking into consideration a number of criteria, can only be solved by using multi-criteria methods PROMETHEE and GAIA. In any case, further research requires a more detailed and complex analysis of the problem. This includes the use of other multi-criteria methods, expansion of input criteria, sensitivity analysis of the change in importance/weight of individual parameters and engaging a large number of experts from different fields in the expert group that defines and analyzes the multi-criteria analysis. Sensitivity analysis warns that multi-criteria analysis, even for the technological criteria respecting certain weights and through them importance of the particular criteria, is an assignment which requires great attention when defining. The presented terminology could be applied for the conventional water supply systems and also for water supply systems driven by other renewable energy sources, i.e., wind, biomass, etc.

Table 4 Sensitivity analysis regarding impact of the change of criteria weights with ranks of the variants regarding balancing periods, with full rank due to $\Phi$

\begin{tabular}{|c|c|c|c|c|c|c|}
\hline$w_{\mathrm{Pel}, \mathrm{PV}}=0.5$ & $w_{\mathrm{W}}=0.25 \quad w_{\mathrm{PS}}=0.25$ & $w_{\mathrm{Pel}, \mathrm{PV}}=0.25$ & $w_{\mathrm{W}}=0.5 \quad w_{\mathrm{PS}}=0.25$ & $w_{\mathrm{Pel}, \mathrm{PV}}=0.25$ & $w_{\mathrm{W}}=0.25$ & $w_{\mathrm{PS}}=0.5$ \\
\hline \multicolumn{7}{|c|}{ Weights combinations for the $w_{\mathrm{Pel}, \mathrm{PV}}, w_{\mathrm{W}}$ and $w_{\mathrm{PS}}$} \\
\hline$t_{\mathrm{b}}=2 ; \Phi=0.2731$ & & $t_{\mathrm{b}}=5 ; \Phi=0.0918$ & & $t_{\mathrm{b}}=2 ; \Phi=0.4078$ & & \\
\hline$t_{\mathrm{b}}=1 ; \Phi=0.1298$ & & $t_{\mathrm{b}}=2 ; \Phi=0.0783$ & & $t_{\mathrm{b}}=3 ; \Phi=0.0711$ & & \\
\hline$t_{\mathrm{b}}=3 ; \Phi=-0.0325$ & & $t_{\mathrm{b}}=4 ; \Phi=0.0671$ & & $t_{\mathrm{b}}=1 ; \Phi=-0.0969$ & & \\
\hline$t_{\mathrm{b}}=4 ; \Phi=-0.1444$ & & $t_{\mathrm{b}}=3 ; \Phi=-0.0188$ & & $t_{\mathrm{b}}=4 ; \Phi=-0.1191$ & & \\
\hline$t_{\mathrm{b}}=5 ; \Phi=-0.2259$ & & $t_{\mathrm{b}}=1 ; \Phi=-0.2185$ & & $t_{\mathrm{b}}=5 ; \Phi=-0.2629$ & & \\
\hline
\end{tabular}


Open Access This article is distributed under the terms of the Creative Commons Attribution 4.0 International License (http://creativeco mmons.org/licenses/by/4.0/), which permits unrestricted use, distribution, and reproduction in any medium, provided you give appropriate credit to the original author(s) and the source, provide a link to the Creative Commons license, and indicate if changes were made.

\section{References}

Brans JP, Vincke P (1985) A preference ranking organisation method: (the PROMETHEE method for multiple criteria decision-making). Manag Sci 31(6):647-656

Brans JP, Vincke Ph, Mareschal B (1986) How to select and how to rank projects: the PROMETHEE method. Eur J Oper Res 24(2):228-238

District of Columbia Water and Sewer Authority-About Drinking Water Quality in Washington, DC, USA. http://www.dcwater.com/ drinking_water/about.cfm. Accessed on 10 Dec 2013

Đurin B (2014) Sustainability of the urban water supply system operating. Ph.D. thesis (on Croatian), Faculty of Civil Engineering, Architecture and Geodesy, University of Split, Split, Croatia

Đurin B, Margeta J (2014) Analysis of the possible use of solar photovoltaic energy in urban water supply systems. Water 6:1546-1561
Macharis C, Springael J, de Brucker K, Verbeke A (2004) PROMETHEE and AHP: the design of operational synergies in multi criteria analysis. Strengthening PROMETHEE with ideas of AHP. Eur J Oper Res 153:307-317

Mareschal B (2014) Manual for visual PROMETHEE academic edition 1.4. http://www.promethee-gaia.net/academic-edition.html. Accessed on 19 Feb 2014

Margeta J (2010) Water supply: planning, design, management and water purification, 1st edn. Faculty of Civil Engineering and Architecture, University of Split, Split, Croatia (in Croatian)

Mladineo N (2009) Support for performance and decision-making in civil engineering (manuscript for the internal use). Faculty of Civil Engineering and Architecture, University of Split, Split, Croatia (in Croatian)

Mutikanga HE, Sharma SK, Vairavamoorthy K (2011) Multi-criteria decision analysis: a strategic planning tool for water loss management. Water Resour Manag 25:3947-3969

Publisher's Note Springer Nature remains neutral with regard to jurisdictional claims in published maps and institutional affiliations. 